\title{
PERISTIWA 4 MEI DI CHINA: REAKSI ORANG CINA DI TANAH MELAYU DAN SINGAPURA
}

\author{
Suffian Mansor
}

\section{Pengenalan}

Peristiwa 4 Mei 1919 merupakan salah satu peristiwa penting dalam sejarah China, di mana pelajar China bersama-sama pelbagai lapisan masyarakat China mengadakan demontrasi untuk mengutuk penyerahan Shantung kepada Jepun. Insiden ini berpunca daripada kegagalan Perjanjian Damai Versailles di Paris (selepas Perang Dunia Pertama) untuk membebaskan China daripada belenggu penjajahan kuasa asing. China yang menyertai Perang Dunia Pertama dengan mengisytiharkan perang ke atas Jerman pada tahun 14 Ogos 1917. ${ }^{1}$ Apabila Perang Dunia Pertama tamat pada pada tahun 1918, China berharap pihak Berikat akan memberi penghargaan kepada mereka kerana sokongan ke atas pihak yang menang. Namun demikian perjanjian tersebut amat mengecewakan China. ${ }^{2}$ Perwakilan China dalam persidangan itu menuntut antara lain adalah tuntutan untuk mendapatkan semula kedaulatan negara mereka. ${ }^{3}$ Tetapi negaranegara Barat and Jepun tidak dapat menerima sepenuhnya permintaan China. Malang bagi China ialah Shantung, bekas wilayah kekuasaan Jerman, diserah kepada Jepun. Atas sebab itu, pada 4 Mei 1919 seramai 5,000 pelajar China di Peking berhimpun and mengadakan bantahan 
di Medan Tiananmen. Di medan itu, mereka mengadakan syarahan mengutuk perjanjian tersebut and mengadakan demontrasi dengan melaung-laungkan slogan, "Pelihara kedaulatan China", "Hukumkan Pengkhianat!" dan "Jangan Tandatangani Perjanjian." di Peking ini terus merebak hampir ke seluruh bandar-bandar di China. Di Tientsin, pelajar-pelajar di Nankai Universiti juga mengadakan protes ke atas perjanjian tersebut. ${ }^{5}$ Di Shantung rapat umum juga diadakan oleh pihak pelajar. Gerakan-gerakan pelajar ini terus mempengaruhi pelbagai lapisan masyarakat China. Pekedai, pedagang, pekerja kilang, buruh kasar, penarik beca dan pihak bank juga mula menyahut seruan daripada pelajar-pelajar China untuk memulaukan barang-barang Jepun. ${ }^{6}$ Kempen pemulauan ke atas barangan Jepun menjalar bukan sahaja ke atas barangan Jepun tetapi juga merebak kepada pemulauan ke atas penggunaan perkhidmatan bank, iklan dan mata wang Jepun. Di sebalik itu mereka telah berkempen untuk menggunakan barangan tempatan. ${ }^{7}$

Impak daripada perjanjian Versailles ini merebak ke Asia Tenggara. Tanah Melayu dan Singapura ketika itu merupakan salah satu jajahan British juga mengalami bahang yang sama. Penduduk Cina yang berada di Negeri-negeri Selat (termasuk juga di Negerinegeri Melayu Bersekutu) turut serta menyokong gerakan pemalauan barangan Jepun. Pertalian mereka dengan negara mereka adalah amat erat sehingga apa sahaja perkembangan di negara mereka akan mempengaruhi mereka. Walaupun mereka berjauhan tetapi ikatan persaudaraan mereka dengan saudara-saudara mereka di China amat rapat. Ini ditambah lagi dengan ikatan nasionalisme orang Cina dikuatkan lagi dengan kedatangan pelbagai aktivis-aktivis politik di tanah besar China. Manakala sekolah-sekolah Cina yang diselenggarakan oleh penduduk Cina sendiri tanpa bantuan kerajaan British juga menyuburkan semangat nasionalisme mereka terhadap tanah besar China. Oleh itu tidak hairan apabila apa sahaja perkembangan di China akan mempengaruni mereka. Sementara jumlah penduduk Cina di Tanah Melayu terutama di Negeri-negeri Selat adalah besar membolehkan impak gerakan mereka menjadi ketakutan oleh penjajahan British. Sebelum membincang lebih lanjut tentang gerakan-gerakan yang dilakukan oleh orang Cina di Tanah Melayu dan Singapura, elok ditinjau dahulu tentang polisi kerajaan kolonial British dan hubungan antara orang Cina di Tanah Melayu dan Singapura dengan negara China. 
Kerajaan Negeri-negeri Selat dan Negeri-negeri Melayu Bersekutu melihat perkembangan gerakan anti-Jepun di China dengan penuh bimbang akan impaknya melanda koloninya di Tanah Melayu. Gabenor Negeri-negeri Selat menyatakan bahawa perkembangan di diingini di Tanah Melayu. Wengelakkan berlaku keadaan yang tidak hanyalah satu perjuangan hanyalah satu perjuangan anti-Jepun tetapi pihak British tidak mahu perkara ini menyebabkan ia akan merebak menjadi anti-British kerana pihak British juga bertanggungjawab dalam memberi sokongan kepada Jepun untuk mendapat wilayah Shantung. Tambahan pula pihak British tidak mahu Tanah Melayu menjadi duri dalam daging dalam hubungannya dengan pihak Jepun. Aktiviti-aktiviti orang Cina ini bukan sahaja akan mengancam ketenteraman dan kestabilan di Tanah Melayu tetapi juga kestabilan Empayar British terutama di India dan rantau Asia Tenggara sehingga ke China.

Perang Dunia Pertama bukan sahaja membawa kesan ke atas negara China tetapi juga kepada kerajaan British terutama dari segi kekuatan ketenteraannya. Walaupun tentera British menang dalam peperangan melawan Jerman dan sekutu-sekutunya tetapi perang ini membawa impak ke atas kelemahan tenteranya. ${ }^{8}$ Selain itu impak perang ini membawa imbangan kuasa di Asia Timur berubah. Jepun mula dianggap sebagai kuasa besar dunia mula mendapat perhatian utama British. British bimbang akan kekuatan Jepun akan mengancam kestabilan rantau Asia Timur. Hubungan mereka dengan Jepun sebelum ini diikat oleh Pakatan Britain-Jepun. Tetapi atas desakan Amerika Syarikat, pakatan ini dibubarkan.' Oleh itu British, yang mempunyai kepentingan ekonomi bukan sahaja di Tanah Melayu tetapi di China, bimbang akan kebangkitan Jepun tanpa ada pakatan ini boleh melemahkan kedudukan mereka di Asia Timur.

Kebangkitan mendadak penduduk Cina dalam menentang Jepun menyebabkan kedudukan British di Tanah Melayu agak sukar. British tidak mahu hubungannya dengan Jepun terjejas atas masalah antiJepun di Tanah Melayu dan Singapura. Atas sebab ini kerajaan British menjalankan polisi yang lebih berhati-hati. Polisi ini diambil kerana British bukan sahaja mahu menjaga hubungannya dengan Jepun tetapi juga dengan China. Di China kemunculan beberapa pemimpinpemimpin Warlord di China selepas kematian Presiden Yuan Shih-kai telah membawa keadaan tidak menentu ke atas suasana politik negara tersebut. Kuasa kerajaan pusat di Peking tidak memain peranan penting dalam menguatkuasakan undang-undang negara. Ini kerana kerajaan 
wilayah yang banyak dikuasai oleh pemimpin Warlord tidak mematuhi arahan kerajaan pusat di Peking. Akibatnya sebahagian besar wilayah China umpama sebuah kerajaan semi merdeka. Walaupun kerajaan China lemah tetapi keinginan orang Cina bersatu amat kuat. Pelajar merupakan eleman penting dalam pencetus gerakan nasionalisme di China. Kuasa pelajar ini mampu mengancam kepentingan kuasa asing di China. British mempunyai kepentingan yang besar di China termasuk dari segi perdagangan, penduduk, mubaligh dan keselamatan tidak mahu kepentingan akan diancam oleh rakyat Cina. ${ }^{10}$ Atas sebab ini kerajaan kolonial British di Tanah Melayu dan Singapura mengambil polisi tunggu dan lihat ke atas aktiviti orang Cina di kedua-dua koloni ini. Pihak kerajaan British membenarkan orang Cina menubuhkan persatuan dan mengadakan kegiatan politik. Namun polisi ini mempunyai hadnya jikalau ia boleh mengancam kepentingan awam dan British sama ada di Tanah Melayu dan Singapura.

\section{Pencetus Nasionalisme Orang Cina}

Bentuk penjajahan oleh kuasa asing di China agak berbeza dengan kebanyakan negara Asia yang dijajah secara langsung. China secara umumnya masih dikuasai oleh orang Cina sendiri. ${ }^{11}$ Namun demikian penguasaan cukainya dan hak pengadilan ke atas masyarakat asing adalah di bawah kekuasaan orang asing. China juga terpaksa memberi banyak lagi keutamaan kepada kuasa asing seperti memberi hak penempatan orang asing di pelabuhan perjanjian dan membenarkan tentera asing berada di China. Tambahan daripada itu beberapa pelabuhan dan wilayahnya dijajah secara langsung seperti Hong Kong, penduduk China dan. Akibat daripada tiada perpaduan di kalangan China sering menjadi mahan pentadbiran China menyebabkan ketinggalan cuba meluaskansa kuasa asing. Jepun juga tidak Tanggapan awal orang Cina kuasa imperialisnya ke atas China. yang harus dicontohi mula berubah Jepun sebagai salah satu negara yang menekan China. Tula berubah apabila Jepun melakukan tindakan dalam Perang Dunia Pertamtan 21 yang diutarakan ke atas China China mula meragui niat menyemarakkan perasaan Jepun ke atas China. ${ }^{12}$ Isu Shantung pula membawa kepada kebangkitan rakya ke atas Jepun. Isu inilah yang Jepun ke atas Shantung kitan rakyat China menentang pendudukan sehingga ke Tanah Melayu. baru. Orang Cina yang datang ke Tanah Melayu tidak memisahkan 
diri mereka dengan negara asal mereka. Mereka mempunyai perasaan taat setia yang kuat terhadap negara mereka. Apa juga berlaku ke atas negara mereka akan mendapat perhatian daripada penduduk Cina ini. Tambahan pula orang Cina seberang laut ini masih mempunyai pertalian kekeluargaan yang erat. Walaupun telah berjauhan dengan keluarga mereka, orang Cina ini tidak lupa akan keluarga dan kampung halaman mereka. Bantuan kewangan juga sering dihantar oleh orang Cina ke China untuk membantu kaum keluarga mereka yang hidup susah. Manakala bencana alam yang sering melanda China juga mendapat perhatian daripada orang Cina ini. Pendek kata hubungan orang Cina dengan negara mereka adalah amat rapat. ${ }^{13}$

Perasaan kesedaran orang Cina di Tanah Melayu dan Singapura terhadap negara mereka boleh dikesan sejak Perang China-Jepun pertama (1894-5) lagi. Detik perang ini boleh dikatakan bermulanya perasaan sayang dan prihatin terhadap negara mereka sendiri. Walau bagaimanapun pada peringkat awal hanya sebahagian kecil pemimpin Cina yang sedar akan masalah negara mereka. Sebahagian besar masyarakat Cina belum lagi dapat menumpu sepenuh perhatian kepada nasib negara mereka kerana sesetengah mereka masih belum dapat mengkukuhkan kedudukan mereka di Tanah Melayu dan Singapura. ${ }^{14}$ Rentetan daripada perang tersebut, perasaan kesedaran tentang nasib negara China mula bercambah. Khoo Seok Wan salah seorang sarjana Cina di Singapura mula menjemput pemimpin China seperti K'ang Yu-wei datang ke Singapura. ${ }^{15}$ Selepas itu beberapa lagi pemimpin nasionalisme China datang ke Tanah Melayu seperti Sun Yat-sen, Yu Lieh, Wang Ching-wei dan Hu Han-min. Maka tumbuhlah beberapa sekolah, majalah dan persatuan yang berunsurkan nasionalisme untuk membela negara China. Antara persatuan yang berpengaruh ialah Tung Meng-hui (TMH). TMH merupakan satu organisasi nasionalisme yang ditubuh pada tahun 1905 di Tokyo. Selepas penubuhan persatuan ini pemimpin-pemimpin TMH China datang ke Tanah Melayu dan Singapura untuk menubuh cawangan TMH di sana. Sambutan penduduk Cina terhadap TMH adalah menggalakkan sehingga membawa kepada penubuhan beberapa cawangan TMH di Singapura, Kuala Lumpur (1906), Seremban dan Kuala Pilah (1907). ${ }^{16}$ Dengan adanya kegiatan berpersatuan yang memandang China sebagai tanahair orang Cina telah menambahkan perasaan kecintaan yang mendalam yang bukan sahaja untuk membela nasib keluarga mereka di China tetapi juga negara mereka yang dibelenggu oleh kelemahan dalaman dan juga tekanan kuasa penjajah asing. 
Sementara itu fenomena anti-Jepun pula bukanlah satu perkara yang baru. Walau bagaimanapun Perang China-Jepun Pertama belum lagi menimbulkan kesan ke atas kebencian terhadap Jepun. Malahan para sarjana China seolah-olah mengkagumi Jepun sebagai salah satu negara Asia yang harus dicontohi. Sebagai contohnya selepas perang tersebut, Reformasi Seratus Hari (1898) menekan betapa pentingnya kerajaan monarki China mencontohi sistem pemerintahan Jepun yang melaksanakan sistem pemerintahan monarki berperlembagaan dan mengadakan pembaharuan dalam aspek pentadbiran, ekonomi dan sosial. ${ }^{17}$ Saranan-saranan daripada reformasi ini juga telah mendapat simpati di kalangan penduduk Cina sama ada di Tanah Melayu mahupun Singapura. Namun demikian perasaan kekaguman terhadap negara Jepun tidak kekal lama. Detik pertama gerakan pemulauan terhadap barangan Jepun bermula pada tahun 1908. Kes menyita Kapal Tatsu Maru (salah satu kapal dagang Jepun) oleh pegawai kerajaan China, menyebabkan timbulnya bantahan daripada kerajaan Jepun. Kerajaan Jepun yang memberi kata dua ke atas kerajaan China untuk menghukum pegawai Cina yang menyita kapal tersebut, meminta ganti rugi dan mohon maaf kepada kerajaan Jepun telah menyebabkan penduduk Cina di Tanah Besar China, Tanah Melayu dan Singapura turut tersinggung. Akibatnya mereka menyahut seruan untuk mengadakan pemulauan barangan Jepun..$^{18}$ Atas sebab-sebab ini orang Cina telah mempunyai asas penting yang menyemarakkan gerakangerakan nasionalisme di Tanah Melayu dan Singapura. Apabila timbulnya Peristiwa 4 Mei 1919, Orang Cina tidak teragak-agak turut serta menyahut kempen pemulauan di Tanah Melayu dan Singapura.

\section{Gerakan Anti-Jepun}

Secara umumnya, di Tanah Melayu dan Singapura, berita-berita mengenai Persidangan Damai di Paris telah bermula dengan penyiaran beberapa rencana dan berita ringkas mengenai rundingan antara pihak yang menang dan kalah. Berita-berita ini termasuklah rangkuman tentang Perjanjian Versailles yang menyenaraikan dengan lengkap tentang butiran perjanjian tersebut. Antara perkara disebut ialah tentang masa depan China yang mendapat haknya semula ke atas beberapa keistimewaan yang diberikan kepada Jerman seperti pembatalan (concessions) Jerman di Hankow dan Tientsin dan Penempatan Austrial Boxer (1901) dengan Jerman. ${ }^{19}$ Selain itu hak Jerman) di Tientsin juga dikg (salah satu kuasa yang besekutu dengan Dipaparkan juga Jepun mendalikan semula kepada kerajaan China. ${ }^{20}$ 
Kiaochow dan Shantung. ${ }^{21}$ Berita mengenai bantahan oleh perwakilan China atas penyerahan hak Jerman ini juga dinyatakan. Perwakilan China menyatakan penyerahan Shantung kepada Jepun adalah satu tamparan ke atas kedaulatan China kerana Shantung dikatakan sebagai kawasan suci negara China. ${ }^{22}$ Malay Mail turut memaparkan satu rencana khas mengenai gerakan anti-Jepun di China. Dalam rencana ini menyatakan bahawa berita mengenai kegagalan Perjanjian Versailles mengembalikan kedaulatan telah disambut dengan demonstrasi yang bermula di Peking. Beratus-ratus risalah berwarna kuning ditaburkan di jalan-jalan di Peking ketika itu, yang mana kandungannya menyatakan bahawa Jepun tidak lagi boleh dilihat sebagai negara yang baik tetapi sebagai musuh baru yang mencabul kedaulatan China dengan mengambil Shantung. Dalam risalah kuning ini mereka membuat seruan ke atas semua lapisan masyarakat untuk mengadakan pemulauan bukan setakat barangan Jepun tetapi juga segala urusan niaga dengan bank-bank milik orang Jepun termasuk penggunaan wang Jepun. ${ }^{23}$

Dengan munculnya berita-berita tentang Perjanjian Versailes, bantahan perwakilan China dan rencana mengenai pemulauan barangan Jepun telah dipaparkan di dada-dada akhbar di Tanah Melayu dan Singapura sejak awal Mei 1919, orang Cina mengambil tindakan berbeza-beza mengikut tempat. Ada antara mereka mengambil tindakan agresif dan tidak kurang juga bersifat pasif. Untuk tujuan ini artikel ini akan memfokuskan impak Peristiwa 4 Mei 1919 ini kepada tiga negeri iaitu Singapura, Pulau Pinang (termasuk Seberang Prai) dan Selangor (tumpuan di Kuala Lumpur).

\section{Singapura}

Di Singapura gerakan anti-Jepun boleh dibahagikan kepada dua peringkat. Peringkat pertama dengan tersebarnya beberapa surat-surat dan nota-nota mula tersebar di kalangan penduduk Cina pada awal bulan Jun 1919. Peringkat ini merupakan peringkat untuk menyedarkan orang Cina akan masalah negara mereka termasuk menyelitkan beritaberita anti-Jepun di China. Surat-surat dan nota-nota ini mengandungi kenyataan-kenyataan keras mengutuk Jepun dan nasib China selepas Perang Dunia I. Kenyataan-kenyataan keras ini membakar semangat patriotik masyarakat Cina untuk membela nasib negara mereka yang dibelenggu oleh kuasa-kuasa imperialisme asing. Petugas-petugas yang menyebar berita ini telah bermula dengan menampal beberapa posterposter dan risalah-risalah di tempat-tempat awam mengenai pemulauan tersebut. ${ }^{24}$ Bermula dengan penyebaran risalah-risalah ini 
juga membawa kepada tindakan pemulauan barangan buatan Jepun bermula. Semua aktiviti ini dianggap sebagai langkah awal atau peringkat awal gerakan ini di Singapura.

Manakala peringkat kedua gerakan ini bermula dengan lebih agresif. Peringkat ini berlaku pada 19 Jun 1919 dengan satu mesyuarat pelajar Cina telah diadakan pada awal pagi di Smith Street. Mesyuarat ini telah memutuskan untuk bertindak lebih tegas dengan memusnah barangan buatan Jepun. Saranan daripada mesyuarat ini telah mendapat perhatian ramai orang Cina. Selepas itu ramai pelajar telah datang untuk menghadiri perhimpunan memulau barang-barang buatan Jepun. Mereka mula mengadakan demontrasi di North Bridge Road dan South Bridge Road, Daerah Kreta Ayer. ${ }^{25}$ Pelajar-pelajar mula bertindak agresif dengan memasuki kedai-kedai orang Cina dan memecah barang-barang buatan Jepun. Demonstrasi pelajar-pelajar Cina ini telah mendapat sambutan dan sokongan daripada golongan pekerja. ${ }^{26}$ Dengan sokongan pekerja ini telah menyemarakkan gerakan anti-Jepun. Sebahagian daripada pekedai-pekedai Cina memberi sokongan kepada tuntutan pelajar ini. Tidak kurang juga pekedaipekedai yang terpaksa akur dengan kehendak pelajar kerana menerima ancaman daripada pelajar-pelajar ini. ${ }^{27}$ Sementara itu peniaga-peniaga Cina yang tidak mengendahkan arahan telah menerima akibat buruk dengan kedai-kedai mereka di pecah masuk dan barang-barang jualan mereka digeledah. ${ }^{28}$ Sementara itu kilang sabun kepunyaan orang Jepun di Syed Alwi Road juga telah digeledah. Perusuh-perusuh ini kemudiannya merampas beratus-ratus kotak sabun. Tindakan merusuh dan memusnahkan barangan Jepun ini telah menimbulkan ketakutan ke atas masyarakat Jepun di Singapura. Atas sebab ini Persatuan Peniaga Jepun telah mengeluarkan arahan agar penduduk Jepun berdiam diri di rumah atau berlindung di Muzium Komersial Jepun. ${ }^{29}$

Untuk meredakan keadaan pihak berkuasa tempatan telah menugaskan pihak polis untuk mengawal keadaan. Kehadiran pihak polis tidak dapat meredakan keadaan sebaliknya menambahkan ketegangan. Orang Cina yang menyertai demonstrasi tersebut telah membaling batu ke arah pihak polis. ${ }^{30}$ Suasana tegang ini menyebabkan pihak polis atas arahan Inspektor yang bertugas telah melepaskan tembakan. Akibat daripada tembakan ini dua orang terbunuh iaitu seorang Cina dan seorang India Muslim. Namun demikian keadaan di Kreta Ayer masih belum reda rusuhan masih lagi berlaku. Akibatnya Gabenor Negeri-negeri Selat, Sir Arthur Young meminta pihak tentera campur tangan. Pihak tentera British pula bersetuju untuk membantu meredakan keadaan di Singapura. ${ }^{31}$ 
Atas sebab ini pihak Pengawal Awam dan sepasukan tentera dari Rejimen Manchester telah dipanggil. Usaha memanggil Blue Jackets dari Kapal Perang HMAS Sydney untuk mengawal keadaan menunjukkan keadaan di Kreta Ayer amat serius. Hanya keesokan harinya keadaan di Kreta Ayer menjadi lebih terkawal dengan tiada sebarang rusuhan berlaku. Walaupun keadaan terkawal namun penduduk Cina masih lagi takut akan tindak-balas daripada golongan penunjuk perasaan anti-Jepun. Sebagai contohnya kebanyakan penarik beca berbangsa Cina tidak kelihatan di jalan-jalan raya. Alasan yang mereka beri ialah beca merupakan salah satu barangan keluaran Jepun. Akibatnya setengah-setengah penarik beca memusnahkan beca-beca yang mereka miliki. ${ }^{32}$

Pada 20 Jun 1919 satu mesyuarat pegawai-pegawai kerajaan British telah diadakan untuk membincangkan lebih lanjut tentang tindakan susulan untuk membendung dan mengawal rusuhan merebak secara berleluasa. Ahli-ahli mesyuarat tersebut melihat keadaan ini adalah serius dan memutuskan untuk mengisytiharkan Undangundang Darurat di Singapura. ${ }^{33}$ Sehubungan itu pihak polis tempatan mula melakukan rondaan sebelah malam untuk memastikan tiada sebarang usaha untuk mewujudkan ketidaktenteraman di Singapura. Kawalan ketat pihak berkuasa tempatan telah berjaya menenangkan semula keadaan. Rusuhan serius yang dianjurkan oleh orang Cina mula beransur kendur. ${ }^{34}$

Kesan daripada gerakan ini menyebabkan seramai 131 orang telah ditangkap. Sementara itu dua kematian yang telah dinyatakan dan satu lagi kematian dilaporkan akibat kecederaan parah kesan cucukan bayonet oleh pihak anggota keselamatan British. Seramai enam orang Cina dan dua orang Tamil cedera. Manakala kepentingan orang Jepun yang mengalami kerugian hanyalah berjumlah kira-kira $\$ 20,080$. Penduduk Jepun pula terselamat dan tidak mengalami kecederaan mahupun kematian. ${ }^{35}$ Menurut laporan Young ketiadaan orang Jepun yang cedera mahupun terkorban dalam gerakan ini kerana gerakan anti-Jepun tidak menumpu kepada serangan kepada penduduk Jepun mahupun kediaman mereka. Gerakan ini lebih menjurus kepada usaha memusnahkan dan memulaukan barangan buatan Jepun. ${ }^{36}$ Namun demikian kes pencerobohan kilang sabun Jepun boleh menafikan alasan. Orang Cina memang juga mempunyai kecondongan untuk menyerang kepentingan Jepun. Mungkin kawalan ketat daripada pihak berkuasa British dan pengawal-pengawal Jepun menyebabkan kepentingan Jepun mengalami sedikit kemusnahan. 


\section{Pulau Pinang}

Reaksi orang Cina di Pulau Pinang terhadap berita mengenai rusuhan dan tangkapan di Peking sejak bulan Mei 1919 telah menimbul rasa simpati terhadap saudara mereka di China. Sebagai tindak-balas awal pemimpin TMH (cawangan Pulau Pinang) telah menghantar kabel yang menyatakan sokongan orang Cina di Pulau Pinang kepada pelajarpelajar di Peking. ${ }^{37}$ Namun demikian reaksi lebih agresif dilakukan oleh orang Cina ini hanya berlaku selepas dua hari rusuhan di Singapura. Sekumpulan kecil orang Cina mula menyerang kedai-kedai dan rumah-rumah kepunyaan orang Jepun. ${ }^{38}$ Kumpulan kecil orang Cina ini mula menarik perhatian awam yang akhirnya menyebabkan jalan-jalan dipenuhi oleh orang ramai. Penarik beca pula memberhentikan perkhidmatan mereka sama ada untuk menyokong gerakan ini atau menghadapi masalah untuk menjalankan perkhidmatan mereka. Pihak sukarelawan tempatan dan polis mula datang untuk menenangkan keadaan. Tetapi pada pagi hari, 23 Jun 1919, orang Cina mengadakan perarakan di Campbell Street, Cintra Street dan Chulliah Street. Sepanjang jalan tersebut mereka merosakkan tingkap dan pintu rumah orang Jepun. Sampai di pusat peniagaan, mereka memecah masuk kedai-kedai dan merosakkan barang-barang buatan Jepun. Beberapa gudang beras juga telah dipecah masuk dan perusuh-perusuh merampas bekalan beras di gudang tersebut. ${ }^{39}$ Akibat daripada seriusnya aktiviti perusuh ini menyebabkan pihak sukarelawan tempatan dan polis telah melepaskan tembakan bagi meleraikan keadaan. Namun perusuh-perusuh ini telah bertindak balas dengan membaling batu dan bersenjatakan kayu untuk melawan pihak sukarelawan tempatan dan polis. Akibat pertempuran kedua-dua pihak ini seramai 25 orang telah ditahan. Dua orang perusuh pula telah cedera manakala seorang lagi telah terbunuh..$^{40}$

Walaupun keadaan pada hari pertama dapat dikawal tetapi pada 24 Jun 1919 perusuh bertindak lebih berani dengan menyerang dua balai polis di Ayer Hitam dan Telok Kumbar. Kedua-dua balai polis ini dikatakan menyimpan bekalan beras dan perusuh yang memecah masuk kedua-dua balai polis ini telah merampas bekalan tersebut. Sementara itu polis di Campbell Street cuba meleraikan perusuh dengan melepaskan tembakan amaran. Namun demikian tembakan amaran ini menyebabkan keadaan bertambah tegang dan seorang perusuh telah ditembak mati. Polis berjaya menahan 37 orang perusuh. Seorang lagi perusuh terbunuh apabila melawan pihak polis di Pragin Road. Akibat daripada tindakan keras kerajaan British, gerakan ini tugas mereka di pejar pekerja-pekerja bangsa Cina tidak meneruskan tugas mereka di pejabat-pejabat kerajaan. Ramai juga pekerja ini tidak 
menyambung tugas mereka. Salah satu perkara menarik dalam rusuhan orang Cina ini ialah orang Melayi dan Tamil juga turut menyertai mereka untuk merampas bekalan beras yang akhirnya mengakibatkan perniagaan di Pulau Pinang terganggu sementara waktu. Keadaan yang tidak terkawal di Pulau Pinang menyebabkan pihak British mengambil langkah untuk mengisytiharkan Undangundang Darurat. ${ }^{41}$

Pada 25 Jun 1919, penduduk Cina di Seberang Prai (Province Wellesly) pula mengadakan rusuhan dan menyekat jalan-jalan di wilayah ini. Walaupun sukarelawan ditugaskan untuk mengawal keadaan tetapi mereka gagal menghalang perusuh dari terus merampas beras dari kedai-kedai tempatan. Untuk mengukuhkan lagi kedudukan pihak British menghalang berlaku rusuhan secara berleluasa, HMAS Sydney dipanggil ke Pulau Pinang dan Seberang Prai. Rusuhan terus menerus berlaku sehingga 28 Jun 1919 di Seberang Prai. Pada masa yang sama Undang-undang Darurat telah diisytiharkan di Seberang Prai. Hanya pada 29 Jun 1919 keadaan di Seberang Prai mula terkawal.

Kesan daripada rusuhan di Pulau Pinang dan Seberang Prai menyebabkan hanya tiga orang Cina terbunuh. Tiga orang Cina lagi cedera akibat bertempur dengan angggota keselamatan. Di Seberang Prai pula tiada kematian dilaporkan. Seorang Cina sahaja dilaporkan cedera. Manakala tangkapan pula adalah 180 orang di Pulau Pinang dan 67 orang di Seberang Prai. ${ }^{42}$ Sementara itu penduduk Jepun tidak mengalami kecederaan mahupun kematian.

\section{Selangor}

Di Selangor, orang Cina tidak berdiam diri tentang seruan pemulauan barangan Jepun. Mereka juga meluahkan perasaan kecewa dan marah mereka terhadap Jepun dengan memusnahkan barang buatan Jepun. Kuala Lumpur menjadi tempat gerakan mereka di Selangor. Berbeza di Singapura dan Pulau Pinang, gerakan pemulauan barangan Jepun di Kuala Lumpur boleh dianggap gerakan yang pasif. Tiada rusuhan berlaku di Kuala Lumpur. Namun demikian pihak berkuasa tempatan dan polis tidak memandang ringan gerakan ini. Setiap gerak-geri orang Cina yang menyertai gerakan ini dipantau untuk mengelak tercetusnya rusuhan seperi berlaku di Singapura dan Pulau Pinang. Keadaan di kedua-dua negeri ini mampu menyemarakkan kemarahan orang Cina di Kuala Lumpur. Kerajaan Negeri-negeri Melayu Bersekutu juga memberi amaran kepada orang Cina supaya tidak menimbulkan kekacauan. Pihak kerajaan telah bersedia untuk mengambil keras bagi menekan mana-mana anasir-anasir yang boleh mengancam keamanan di Negeri-negeri Bersekutu. Satu kenyataan keras daripada kerajaan 
kolonial telah dikeluarkan untuk memberi amaran kepada orang Cina agar bersikap bertanggungjawab dan mengelak sebarang kekacauan yang mengancam harta-benda dan nyawa orang awam. ${ }^{43}$

Oleh sebab tekanan dan amaran daripada kerajaan kolonial ini menyebabkan aktiviti-aktiviti pemulauan ke atas Jepun dilakukan dengan skala yang kecil dan aman. Pusat aktiviti pemulauan barangan Jepun ini dilakukan di Petaling Street. Petaling Street adalah salah satu penempatan utama orang Cina di Kuala Lumpur yang menyaksikan orang Cina mengadakan bantahan mereka dengan memusnahkan barang-barang Jepun. Kesemua barang-barang ini adalah milik orang Cina itu sendiri. Oleh itu pihak berkuasa tempatan dan polis tidak mengambil sebarang tindakan ke atas mereka. Rentetan daripada aktiviti ini, orang Cina mengambil tindakan untuk tidak membeli barangan buatan Jepun. ${ }^{44}$ Atas sikap pasif orang Cina Kuala Lumpur ini tidak membawa kepada pertempuran antara orang Cina dan pihak polis seperti yang berlaku di Singapura dan Pulau Pinang. Keadaan di Kuala Lumpur secara umumnya adalah aman tanpa sebarang tindakan yang cuba mengancam keselamatan dan ketenteraman awam. ${ }^{45}$

Pihak berkuasa di Kuala Lumpur juga bertindak cekap dengan mematahkan sebarang usaha untuk menyemarakkan semangat antiJepun di kalangan orang Cina daripada bertindak pasif kepada agresif. Pihak berkuasa telah dapat menghidu lebih awal akan tindakan sesetengah orang Cina yang cuba menyebar propaganda anti Jepun. Terdapat juga surat-surat dan risalah-risalah yang bernada keras menentang Jepun telah ditampal dan diedarkan kepada penduduk Cina di Kuala Lumpur. ${ }^{46}$ Namun usaha ini gagal mendapat sambutan orang Cina untuk mengadakan rusuhan di Kuala Lumpur. Kegagalan untuk menimbulkan huru-hara di Kuala Lumpur tidak mengakhiri usaha golongan radikal Cina untuk terus menyebar propaganda mereka. Golongan ini dikatakan cuba menghalang orang Cina daripada menyertai Perarakan Kemenangan tentera Berikat pada Julai 1919 tetapi gagal. Untuk menghalang lebih banyak lagi usaha untuk menyebar propaganda-propaganda anti-Jepun ini oleh golongan radikal Cina ini, pihak kolonial British telah menggunakan Banishment Enactment untuk menangkap dan menghantar pulang orang Cina yang disyaki mengapi-apikan kemarahan orang Cina. ${ }^{47}$ Dengan kawalan ketat daripada pihak berkuasa British telah berjaya menggagalkan usaha untuk mencetuskan huru-hara di Kuala Lumpur. 


\section{Kesimpulan}

Peristiwa 4 Mei 1919 merupakan salah satu tarikh penting kepada negara China. Malahan orang Cina di Tanah Melayu dan Singapura yang mempunyai pertalian yang kuat dengan gerakan-gerakan politik di China, telah menunjukkan sokongan mereka menerusi kempenkempen anti-Jepun. Semua barangan berkaitan dengan Jepun telah menjadi mangsa kemarahan orang Cina ini. Malahan beca yang dikaitkan dengan Jepun juga telah menjadi sasaran kebencian orang Cina. Walaupun kempen-kempen anti-Jepun ini amat jelas berlaku di Singapura, Pulau Pinang dan Kuala Lumpur, ini tidak bermakna orang Cina di tempat-tempat lain tidak mempunyai perasaan anti-Jepun yang mendalam. Oleh sebab ketiadaan bahan mengenai gerakan-gerakan ini di tempat-tempat lain, maka agak sukar untuk mengukur orang Cina ini tidak mempunyai sentimen yang sama dengan orang Cina di Singapura, Pulau Pinang dan Kuala Lumpur. Sentimen anti-Jepun ini mungkin ada tetapi tidak menonjol seperti penduduk Cina di tiga tempat ini.

Perlu diingatkan juga peranan penting yang dimainkan oleh kerajaan kolonial British untuk menyekat gerakan ini daripada menjadi satu gerakan di seluruh Tanah Melayu dan Singapura ia merupakan salah satu faktor penting bagi membendung gerakan ini daripada menjalar ke tempat-tempat lain. British tidak mahu gerakan ini mengancam suasana aman damai di Tanah Melayu yang akan menjejaskan kepentingan ekonomi mereka, telah bertindak tegas menghalang orang Cina daripada terus mengadakan rusuhan. Selain itu di peringkat dunia pula, kerajaan British di London amat mementingkan agar koloninya di Asia Tenggara tidak mengeruhkan hubungannya dengan Jepun. Selepas Perang Dunia I, British belum lagi bersedia untuk berhadapan dengan Jepun yang mana perang ini telah menaikkan imej Jepun sebagai kuasa Asia yang kuat dan juga muncul sebagai kuasa dunia setanding dengan kuasa Barat yang lain. Atas sebab-sebab ini maka kerajaan koloni British sama ada di Tanah Melayu dan Singapura serta London mengarahkan pasukan tentera untuk membantu pihak polis untuk memadamkan gerakan ini. Akibatnya gerakan anti-Jepun semakin mengendur selepas Julai 1919.45

Mengenai sebab berlaku kekacauan di Pulau Pinang, Gabenor Negeri-negeri Selat, Young, menyatakan sebab meletus kekacauan di Pulau Pinang bukannya semata-mata disebabkan gerakan anti-Jepun di China tetapi juga ćisebabkan harga beras yang naik. Oleh sebab beras merupakan makanan ruji bagi penduduk Tanah Melayu, maka peningkatan harga yang tinggi menyebabkan kesusahan kepada penduduk Tanah Melayu. Kenaikan harga beras ini telah dilaporkan 
sejak tahun 1918 lagi." Masalah ini berterusan sehingga pertengahan Mei 1419.50 Atas sebab ini berlaku rusthan di tempat menyimpan betas. Oleh itu Young telah mencadangkan agar harga beras diturunkan kerana ini bolch diterima sebagai salah satu sebab yang sedia ada. Manakala Peristiwa 4 Mei 1919 sebagai penggerak kepada kemarahan ini. Ini tidak bermakna orang Cina di Pulau Pinang hanya melakukan rusuhan ini disebabkan beras. Pexistiwa 4 Mei 1919 adalah sebab utama yang menyebabkan semata-mata orang Cina mengadakan perarakan anti-Jepun. Ini kerana rusuhan di I'ulau Pinang bermula daripada perarakan anti Jepun. A pabila gerakan ini mendapat sambutan orang ramai termasuk bangsa lain maka isu beras mula timbul. Maka mereka pun menggunakan peluang ini untuk merusuh dan mencerobohi gudang-gudang beras kerajaan kolonial dan kedai-kedai beras.

Jikalau diamati dengan penuh teliti tentang insiden ini di China, ia bukan semata-mata gerakan politik menentang Perjanjian Versailles. Insiden ini merupakan salah satu rangkuman gerakan politik dan kebudayaan di China. ${ }^{51}$ Golongan intelektual Cina seperti Ch'en Tuhsiu dan Hu Shih merupakan penggerak utama revolusi budaya masyarakat Cina di tanah besar. ${ }^{52}$ Ch'en Tu-hsiu dan Hu Shih telah mengajak masyarakat Cina untuk berubah daripada kekangan dan ketaksuban terhadap ajaran tradisional China. Sejauh mana peranan golongan intelektual Cina ini membawa revolusi budaya di Tanah Melayu dan Singapura merupakan salah satu perkara yang menarik untuk dikaji. Di dalam artikel ini, perbincangan condong kepada gerakan politik. Diharap kajian mengenai gerakan revolusi budaya boleh merjadi satu kajian yang lebih menarik untuk melihat sama gerakan revolusi budaya juga berlaku di kalangan orang Cina di Tanah Melayu dan Singapura seperti berlaku di China. 
Nota

1

Pengisytiharan perang ini membawa krisis daiaman di China. Perdana Menteri Tuan Ch'i-jui yang menganjur cadangan pengisytiharan perang ini menghadapai tentangan daripada Presiden Li Yuan-hung. Namun tentangan ini tidak dapat menghalang Tuan daripada meneruskan usaha-usahanya apabila Li disingkir daripada jawatan

David Armstrong, 'China's Place in the New Pacific Order', Erik Goldstein and John Maurer (cds.), The Washingion Conference, 192J-22: Natal Rizalry, East Asian Stability and the Road to Pearl Harbour, Ilford: Frank Cass, 1994, hal.249. 257.

$1 \quad$ Baì

of China 1919.1949, Foreign Chae-jin Lee, Zhon Entai: The Early Years, Stanford: Stanford University Press, 1994, hal.121.

- PRO FO228/3285 Tientsin Inteligent Report, June Quarter. 1919, hal.2.

$7 \quad$ PRO FO228/3285 Extract from Tientsin Intelligent Report, September Quarter. 1919, hat.1.

B Erik Goldstein, 'The Evolution of British Diplomacy: Strategy for the Washington Conference', Erik Goldstein and John Maturer (eds.), The Washington Conference, 1921-22: Naval Rivalty, East Asian Stability and the Road to Pearl Harbotur, Frank Cass: IIford, 1994, hal.5 dan P. A. Reynolds, British Foreign Policy in the Inter-War Years, London: Longmans, Green and Co., 1954, hal.169-202.

- Jan Nish, 'Echoes of Alliance, 1920-1930,' lan Nish and Yoichi Kibata (eds), The History of Anglo-Iapanese Relations, Volume l, The PoliticatDiplonatic Dimension, 1600-1930, Macmillan London: Press Ltd., 2000, hal.255.

Robert Bickers, Brifain in China, Manchester University Press: Manchester, 1999, hal.117 and Edmund S. K. Fung, The Diplomacy of Imperial Retreat: Brilain's South China Policy. 1924-1931, Hong Kong:

is Oxford University Press, 1991, hal.81.

it Jürgen Osterhammel, 'Semi-Colonialism and Informal Empire in Twentieth-Century China: Towards a Framework of Analysis', Wolfgang J. Mommsen and Jürgen Osterhammel, Imperialism and After and

12 Discontinuitte's, London: Allen \& Unwin, 1985, hal.290. Wm. Roger Louis, British Sirategy in the Far East, 1919-1939, Oxford: Clarendion Press, 1971, p.17.

13 Yen Ching-hwang, Commumity and Politics: the Chinese in Colonial 14 Singapore ard Maldyysia, Singapore: Times Academic Press, 1995, hal.200. Stephen Mun Yoon Leong, 'Sources, Agenties and Manifestations of Overseas Chinese Nationalism in Malayn, 1937-1942, "t.1", (unpublished Ph. D., University Microfilms Inlernational, Ann Arbor, Michigan, USA, London, England, 1976), hal.22 dan 28. 
is Stuphen Mun roon Leong, 'Sources, Agencies and Manifestations,' hal.23.

is Stefthen Mun Yoon Leong, 'Sources, Agencies and Manifestations,' hal..78 dan 40.

17 The Roform Motwnett of 1898, Forcign Languages Press: 1976, hal.25 dan 26.

18 Stephen Mun Yoon Leong, 'Sources, Agencies and Manifestations, hal. $5 \div-55$.

is Sprecial Edition Malay Mail, 10 May 1919, hal.2.

20 Rasmussen, Tlte Growth of Tit'tsin, Tientsin: Tientsin Press, Ltd., 1924, hal. 42 and 48 .

2. Spicial liuton Wolats Mait, 10 May 1919, hal.2.

22 Miluy Mail, 10 May 1919, hal.7.

23 Maliz Mand, 24 May 1919, hal.6.

24 Molay Mail. 18 june 1919, hal.6.

25 PRO FO288/3466 Letter from Arthur Young to Viscount Milner, Singapore, 26"11 July, 1919, hal.2 dan 3.

76 Stephen Mun Yoon Leong, 'Soturces, Agencies and Manifestations;' hali.65.

27 YOAS, the SCRR, Wilfred Blythe Collection, Governor (Sir Arthur Young) to S. of S. (Viscounl Milner, P.C. CCB, GCMG, etc.) dd. 26 July, 1919. hal.13.

PRO FO288/3466 Letter from Arthur Young to Viscount Milner, Singapore, 26" Jt1ly, 1919, hal.2 dan 3.

Stephen Mun Yoon Leong, 'Sources, Agencies and Manifestations,' hal.65 - 66 .

SOAS, the SCRR, Wilfred Blythe Collection, Governor (Sir Arthur Young) to S. of S. (Viscount Milner, P.C. CCB. GCMG, ete) dd. 26 July, 1919, hal.13.

SOAS, the SCRR, Wilfred Blythe Collection, Governor (Sir Arthur Young) to S. of S. (Viscount Milner, P.C. CCB, GCMG, etc.) dd. 26 july, 1919, hal.13.

l'RO FO288/3466 Letter from Arthur Young to Viscount Milner, Singapore, 26 ${ }^{\text {th }}$ July, 1919, hal.3.

SOAS, the SCRR, Wilfred Blythe Collection, Governor (Sir Arthur Young) to S. of S. (Viscount Milner, P.C. CCB, GCMG, etc.) dd. 26 July,
1919, hal.13.

PRO FO288/3466 Letter from Arthur Young to Viscount Milner, Singspore, $26^{\text {th }}$ July, 1919, hal.3 dan 4.

Singapore, 26 (4) Letter from Arthur Young to Viscount Milner, Singapore, $26^{4 \prime}$ July, 1919, hal.4.

YoAs, the SCRR, Wilfred Blythe Collection, Governor (Sir Arthur 1919. hal.13.

Stiphin Mun Yoon Leong, Sour hal.64. 
38

SOAS, the SCRR, Wilfred Blythe Collection, Governor (Sir Arthur 1919, hal.14.

39 The Malay Mail, 24 June 1919, hal.7.

4)

PRO FO288/3466 Letter from Arthur Young to Viscount Milner, Singapore, $26^{\text {th }}$ July, 1919, hal.4-5. PRO FO288/3466 Letter from Arthur Young to Viscount Milner,
Singapore, 26" July, 1919, hal.5.

42 PRO FO288/3466 Letter from Arthur Young to Viscount Milner, Singapore, $26^{\mathrm{U}}$ July, 1919, hal.5-6.

43 Mriny Mails 23 June 1919, hal.6.

4 Malay Mail, 23 June 1919, hal.6.

45 PRO CO439/3, Selangor Annual Report for the year 1919 by A. H. Lemon, hal.12.

PRO CO439/3, Selangor Annual Report for the year 1919 by A. H. Lemon, hal.12.

4

PRO CO439/3, Selangor Annual Report for the year 1919 by A. H. Lemon, hal.12.

1- Stepher Mun Yoon Leong, 'Sources, Agencies and Marifestations,' hal.70.

19 PRO FO288/3466 Letter from Arthur Young to Viscount Milner, Singapore, $26^{\mathrm{H}} \mathrm{July}, 1919$, hal.6.

5o Malay Mail, 12 May 1919, hal.6.

s1 Arthur N. Holcombe, The Chinese Revolution: A Phase in the Regeneration of A World Power Cambridge: Harvard University Press, 1930, hal.435.

32 Jerome B. Grieder, 'Communism, Nationalism, and Democracy: The Chinese Intelligentsia and the Chinese Revolution in the 1920's and 1930's', Modern East Asia: Essays in interpretation, Yale: Yale University Press, 1970, hal.211. 